\title{
Association Between Serum Vitamin D Levels and Frequency of Relapses in Patients With Multiple Sclerosis
}

Farah Mansoor ${ }^{1}$, Vikash Kumar ${ }^{2}$, Suneel Kumar ${ }^{2}$, Navneet Kaur ${ }^{3}$, Sidra Naz ${ }^{4}$, Simra Shahid ${ }^{5}$, Faryal Anees ${ }^{6,1}$, Sidra Memon ${ }^{1}$, Amber Rizwan ${ }^{7}$

1. Internal Medicine, Jinnah Sindh Medical University, Karachi, PAK 2. Neurology, Ghulam Muhammad Mahar Medical College, Sukkur, PAK 3. Internal Medicine, Adesh institute of Medical Sciences and Research, Bathinda, IND 4. Internal Medicine, University of Health Sciences, Lahore, PAK 5. Medicine, Jinnah Sindh Medical University, Karachi, PAK 6. Obstetrics and Gynecology, Agha Khan University Hospital, Karachi, PAK 7. Family Medicine, Jinnah Post Graduate Medical Center, Karachi, PAK

Corresponding author: Farah Mansoor, farahmansoor06@gmail.com

\section{Abstract \\ Introduction}

Multiple sclerosis (MS) is an immune-mediated inflammatory disease of the central nervous system affecting the myelin sheath of neurons with a wide range of symptoms. Among various risk factors studied that can increase the relapse, vitamin D is also a potential risk factor. In this study, we will determine the association between vitamin D status and frequency of relapses in patients with MS.

\section{Material and methods}

Seventy-four (74) patients with a confirmed diagnosis of MS, with more than one (01) relapse per year, for a minimum of two years, were included in the case group. Seventy-four (74) participants with a confirmed diagnosis of MS with one (01) or no relapse per year, for a minimum of two years, were included in the control group. After informed consent, the patient blood was drawn via phlebotomy and was sent to the lab for vitamin D levels.

\section{Results}

The mean serum vitamin D level was significantly lower in case group compared to control group (18.21 \pm $4.21 \mathrm{ng} / \mathrm{mL}$ vs. $29.21 \pm 5.72 \mathrm{ng} / \mathrm{mL}$; p-value: < 0.0001 ). The number of participants with vitamin D level less than $30 \mathrm{ng} / \mathrm{mL}$ were significantly higher in patients with case group compared to control group $(78.37 \% \mathrm{vs}$. 50.0\%; p-value: 0.0003 )

\section{Conclusion}

Review began 04/05/2021 Review ended 04/06/2021 Published 04/09/2021

\section{๑) Copyright 2021}

Mansoor et al. This is an open access article distributed under the terms of the Creative Commons Attribution License CC-BY 4.0., which permits unrestricted use, distribution, and reproduction in any medium, provided the original author and source are credited.
In this study, patients with more relapses per year had low level of serum vitamin D. There is emerging strong evidence that vitamin D plays an important role in the pathogenesis, progression, and disease burden of autoimmune disease, including MS.

\author{
Categories: Neurology \\ Keywords: multiple sclerosis, vitamin d, association, relapses
}

\section{Introduction}

Multiple sclerosis (MS) is an immune-mediated inflammatory disease of the central nervous system affecting the myelin sheath of neurons with a wide range of symptoms. The prevalence of MS varies from high levels in North America and Europe (>100/100,000 inhabitants) to low levels in Eastern Asia and sub-Saharan Africa (2/100,000 population) [1]. The sensory symptoms and fatigue occur early in the disease course; while loss of mobility, fatigue, bowel/bladder dysfunction and spasticity are more commonly reported in later stage of disease [2]. The age of onset most commonly can range from 15 to 50 years and females are commonly affected [3].

Primarily, there are two forms of MS: relapsing and progressive [4]. Relapses pose numerous challenges to health care providers in the management of MS, and they can also significantly increase the cost of management of MS and decrease the quality of life of patients [5,6]. It is important to identify various risks associated with increased risk of relapse and mitigate them to reduce the frequency of relapses [7]. Various risk factors such as age, bacterial infection, vitamin D levels, sex, and pregnancy have been discussed in various studies as potential risk factors for relapses [8]. In this study, we will determine the association between Vitamin D status and frequency of relapses in patients with MS in local setting. 


\section{Cureus}

\section{Materials And Methods}

This case-control was conducted in the neurology department of various tertiary care hospitals from November 2017 to May 2020. Seventy-four (74) patients with a confirmed diagnosis of MS, with more than one (01) relapse per year, for a minimum of two years, were included in the case group. As a reference, seventy-four (74) participants with a confirmed diagnosis of MS with one (01) or no relapse per year, for a minimum of two years, were included in the control group. Participants taking vitamin D supplements were excluded from the study. MS was confirmed with magnetic resonance imaging (MRI), clinical symptoms, and cerebrospinal fluid analysis. Relapse was defined as a neurologic deficit associated with an acute inflammatory demyelinating event that lasts at least 24 hours in the absence of fever and infection [9]. Patient extended disability status scale (EDSS) was noted. After informed consent, the patient blood was drawn via phlebotomy and was sent to the lab for Vitamin D levels. Patients with vitamin D levels of less than $30 \mathrm{ng} / \mathrm{ml}$ were classified as Hypovitaminosis [10].

Statistical analysis was done using SPSS v. 22.0 (IBM Corporation, Armonk, NY, United States). Continuous variables, including age, duration of disease, number of relapses and mean vitamin $\mathrm{D}$ levels, were presented as mean and standard deviation. Categorical variables, including gender, treatment, and hypovitaminosis, were presented as percentages and frequencies. An Independent T-test was applied to compare the numerical values. Chi-square was applied to compare categorical data between the two groups. A p-value of less than 0.05 represented a difference between the case and control group and the null hypothesis was void.

\section{Results}

The mean age of participants in the case group was $38 \pm 6$ years and for the control group, it was $37 \pm 5$ years. The EDSS score was $3.21 \pm 1.02$ for the case group and $3.11 \pm 1.11$ for the control group. However, differences between the two groups for age, time since diagnosis, EDSS score, were non-significant. The number of relapses in the case group was significantly higher compared to the control group (Table 1).

\begin{tabular}{|c|c|c|c|}
\hline Characteristics & Case group $(n=74)$ & Control group $(n=74)$ & $p$-value \\
\hline Age (in years) & $38 \pm 6$ & $37 \pm 5$ & 0.27 \\
\hline Time since diagnosis (years) & $4.4 \pm 2.1$ & $4.2 \pm 2.4$ & 0.59 \\
\hline Female (\%) & $49(66.2)$ & $50(67.5)$ & 0.86 \\
\hline Extended disability status scale score (mean \pm SD) & $3.21 \pm 1.02$ & $3.11 \pm 1.11$ & 0.56 \\
\hline No of relapse per year (mean $\pm S D$ ) & $1.31 \pm 0.58$ & $0.52 \pm 0.21$ & $<0.0001$ \\
\hline \multicolumn{4}{|l|}{ Current treatment } \\
\hline Steroids & $31(41.9)$ & $28(37.8)$ & \multirow{3}{*}{0.56} \\
\hline Interferon & $23(31.1)$ & $20(27.0)$ & \\
\hline Anti-CD-20 therapy & $20(27.0)$ & $26(35.1)$ & \\
\hline
\end{tabular}

\section{TABLE 1: Characteristics of case and control group.}

CD-20; B-lymphocyte antigen CD20.

The mean vitamin D level was significantly lower in case group compared to control group (18.21 \pm 4.21 $\mathrm{ng} / \mathrm{mL}$ vs. $29.21 \pm 5.72 \mathrm{ng} / \mathrm{mL}$; $\mathrm{p}$-value: < 0.0001). The number of participants with vitamin $\mathrm{D}$ level less than $30 \mathrm{ng} / \mathrm{mL}$ were significantly higher in patients with case group compared to control group (78.37\% vs. 50.0\%; p-value: 0.0003) (Table 2).

\begin{tabular}{|c|c|c|c|}
\hline Vitamin D level & Case group $(n=74)$ & Control group $(n=74)$ & p-value \\
\hline Mean value $(\mathrm{ng} / \mathrm{mL})$ & $18.21 \pm 4.21$ & $29.21 \pm 5.72$ & $<0.0001$ \\
\hline Hypovitaminosis (\%) & $58(78.37)$ & $37(50.0)$ & 0.0003 \\
\hline
\end{tabular}

TABLE 2: Vitamin D status in case and control group. 


\section{Discussion}

In our study, patients of MS with more than one relapse per year had lower level of serum vitamin D level compared to patients of MS with less than one relapse per year. The case group also reported a higher prevalence of hypovitaminosis compared to control group.

Prior studies have shown that vitamin D levels are known to play a major role in MS. Munger et al. conducted a study in which the white participants proved the correlation between increased levels of 25-

hydroxyvitamin D and decreased risk of MS; however, the blacks and Hispanics in the same study showed no significant relation between MS and vitamin D [11].

Various studies point out that vitamin D may not only be an environmental risk factor for the development of MS but may also play an important role in modulating disease activity and progression. Various studies point out that low vitamin D levels have been associated with increase relapse rate, like our study [12]. Low vitamin D level may also be responsible for increase disability and increase lesion load on magnetic resonance imaging (MRI) [13,14]. In recent years, numerous studies have been done to investigate if there is any role of vitamin D supplements in management of MS; however, based on systemic review done in 2020, the results are contradictory. Few studies show the benefit of Vitamin D supplements in reducing disease burden in MS patients and while few studies suggest otherwise [15].

However not every study has reported association between vitamin D levels and MS. Fragoso et al. in his study demonstrated that MS patients and control group had no significant differences between their vitamin D levels [16]. Some studies, focused on the disease activity, proved no interconnection between vitamin D and MS. Rito et al. in his study showed that there is no link between EDSS scores and vitamin D levels [17].

Vitamin D levels have been known to play particularly important role in other autoimmune diseases as well. Some studies have specified that the low vitamin D levels may be an important factor in the development of autoimmune diseases as several epidemiological studies have stated that there is a strong correlation between insufficient vitamin D and incidence of autoimmune diseases, like type 1 diabetes mellitus (T1D), systemic lupus erythematosus (SLE), rheumatoid arthritis (RA) and inflammatory bowel disease (IBD) $[18,19]$. In animal models for T1D, MS, SLE, IBD, and autoimmune uveitis, calcitriol proved to either avoid or enhance autoimmunity. Studies that dealt with vitamin D deficient animals proved increased inflammatory response and vulnerability to T1D and Crohn's disease and were prone to be invaded by bacteria and infections [20].

To the best of our knowledge, this is the first study from Pakistan that studies the association of vitamin D level and frequency of relapses in MS patients. The study was conducted in various hospitals, allowing the sample to be diverse. However, further large-scale studies are needed to study Vitamin D level influence on various aspects of MS disease, including relapses, disability, and MRI lesion loads. If proven effective in local setting, Vitamin D may provide a cheap option in addition to existing therapies, to reduce relapses, disability, and disease burden, which may reduce the overall cost of management of MS and improve quality of life in MS patients.

\section{Conclusions}

In this study, patients with more relapses per year had low level of serum vitamin D. There is emerging strong evidence that vitamin D plays an important role in the pathogenesis, progression, and disease burden of autoimmune disease, including MS. Therefore, it is important that various investigatory trials should be done to understand the role of vitamin D in MS pathogenesis and to determine its role in the management of MS.

\section{Additional Information}

\section{Disclosures}

Human subjects: Consent was obtained or waived by all participants in this study. Ghulam Muhammad Mahar Medical College issued approval GMMMC/IRB-Off/2017-N-11. Animal subjects: All authors have confirmed that this study did not involve animal subjects or tissue. Conflicts of interest: In compliance with the ICMJE uniform disclosure form, all authors declare the following: Payment/services info: All authors have declared that no financial support was received from any organization for the submitted work. Financial relationships: All authors have declared that they have no financial relationships at present or within the previous three years with any organizations that might have an interest in the submitted work. Other relationships: All authors have declared that there are no other relationships or activities that could appear to have influenced the submitted work.

\section{References}

1. Leray E, Moreau T, Fromont A, Edan G: Epidemiology of multiple sclerosis . Rev Neurol. 2016, 172:3-13. 10.1016/j.neurol.2015.10.006

2. Fox RJ, Bacon TE, Chamot E, Salter AR, Cutter GR, Kalina JT, Kister I: Prevalence of multiple sclerosis 
symptoms across lifespan: data from the NARCOMS Registry. Neurodegener Dis Manag. 2015, 5:3-10. 10.2217/nmt.15.55

3. Goldenberg MM: Multiple sclerosis review. P T. 2012, 37:175-84.

4. Lublin FD, Reingold SC: Defining the clinical course of multiple sclerosis: results of an international survey. National Multiple Sclerosis Society (USA) Advisory Committee on Clinical Trials of New Agents in Multiple Sclerosis. Neurology. 1996, 46:907-11. 10.1212/wnl.46.4.907

5. Polman CH, Reingold SC, Banwell B, et al.: Diagnostic criteria for multiple sclerosis: 2010 revisions to the McDonald criteria. Ann Neurol. 2011, 69:292-302. 10.1002/ana.22366

6. Raimundo K, Tian H, Zhou H, Zhang X, Kahler KH, Agashivala N, Kim E: Resource utilization, costs and treatment patterns of switching and discontinuing treatment of MS patients with high relapse activity. BMC Health Serv Res. 2013, 13:131. 10.1186/1472-6963-13-131

7. Blahova Dusankova J, Kalincik T, Dolezal T, Kobelt G, Havrdova E: Cost of multiple sclerosis in the Czech Republic: the COMS study. Mult Scler. 2012, 18:662-8. 10.1177/1352458511424422

8. Kamel FO: Factors involved in relapse of multiple sclerosis . J Microsc Ultrastruct. 2019, 7:103-8. 10.4103/JMAU.JMAU_59_18

9. Sevim S: Relapses in multiple sclerosis: definition, pathophysiology, features, imitators, and treatment . Turk J Neurol. 2016, 22:99-108. 10.4274/tnd.75318

10. Holick MF: High prevalence of vitamin D inadequacy and implications for health . Mayo Clin Proc. 2006, 81:353-73. 10.4065/81.3.353

11. Munger KL, Levin LI, Hollis BW, Howard NS, Ascherio A: Serum 25-hydroxyvitamin D levels and risk of multiple sclerosis. JAMA. 2006, 296:2832-8. 10.1001/jama.296.23.2832

12. Fitzgerald KC, Munger KL, Köchert K, et al.: Association of vitamin D levels with multiple sclerosis activity and progression in patients receiving interferon beta-1b. JAMA Neurol. 2015, 72:1458-65. 10.1001/jamaneurol.2015.2742

13. Smolders J, Torkildsen $\emptyset$, Camu W, Holmøy T: An update on vitamin D and disease activity in multiple sclerosis. CNS Drugs. 2019, 33:1187-99. 10.1007/s40263-019-00674-8

14. Ascherio A, Munger KL, White R, et al.: Vitamin D as an early predictor of multiple sclerosis activity and progression. JAMA Neurol. 2014, 71:306-14. 10.1001/jamaneurol.2013.5993

15. Feige J, Moser T, Bieler L, Schwenker K, Hauer L, Sellner J: Vitamin D Supplementation in Multiple Sclerosis: A Critical Analysis of Potentials and Threats. Nutrients. 2020, 12:10.3390/nu12030783

16. Fragoso YD, Adoni T, Alves-Leon SV, et al.: No correlation was observed between vitamin D levels and disability of patients with multiple sclerosis between latitudes $18^{\circ}$ and $30^{\circ}$ South. Arq Neuropsiquiatr. 2017 75:3-8. 10.1590/0004-282X20160173

17. Rito Y, Flores J, Fernández-Aguilar A, Escalante-Membrillo C, Barboza MA, Amezcua L, Corona T: Vitamin $\mathrm{D}$ and disability in relapsing-remitting multiple sclerosis in patients with a Mexican background. Acta Neurol Belg. 2018, 118:47-52. 10.1007/s13760-017-0834-3

18. Cantorna MT, Zhu Y, Froicu M, Wittke A: Vitamin D status, 1,25-dihydroxyvitamin D3, and the immune system. Am J Clin Nutr. 2004, 80:1717S-20S. 10.1093/ajcn/80.6.1717S

19. Bock G, Pieber TR, Prietl B: Vitamin D: role in autoimmunity. CAB Rev. 2012, 7:10.1079/PAVSNNR20127041

20. Antico A, Tampoia M, Tozzoli R, Bizzaro N: Can supplementation with vitamin D reduce the risk or modify the course of autoimmune diseases? A systematic review of the literature. Autoimmun Rev. 2012, 12:12736. 10.1016/j.autrev.2012.07.007 